\title{
Funeral directors, mortuaries and necropsies: implications for necropsy consent rates and the prevention of infection
}

\author{
R D Start, A Dube, S S Cross, J C E Underwood
}

\begin{abstract}
Aim-To evaluate the attitudes and experiences of funeral directors in relation to necropsies.

Methods-All 1631 members of the National Association of Funeral Directors were surveyed by postal questionnaire about the purposes of necropsies, the technical and administrative problems associated with necropsied cases and their relations with relatives, mortuaries and pathology departments.
\end{abstract}

Results-In total, 123 funeral directors completed the questionnaire $(8 \%$ response rate). Workload, proportion of cases necropsied and type of mortuary did not influence answers. Necropsies were considered important for the assessment of treatment outcome, identification of inherited disease and junior pathologist training, but not for medical audit. There was strong support for more education about necropsies. The areas of necropsy practice most frequently discussed with relatives related to concerns about funeral delay and the involvement of the coroner or equivalent authority. Funeral directors occasionally counselled relatives for or against giving necropsy consent. The commonest technical problems associated with necropsies were difficulties in embalming, leakage of body fluids and scalpel penetration in visible areas. Few administrative problems were reported; the commonest was inflexibility in body collection times. There was strong support for a national code of practice to cover relations between funeral directors and mortuaries despite general satisfaction with relations with local pathology departments.

Conclusions-Although the relation among the funeral profession, mortuaries and pathology departments is largely satisfactory, a national code of practice for funeral directors and mortuaries is desirable.

(f Clin Pathol 1996;49:217-222)

Pathology, Sheffield University Medical School, Beech Hill Road, Sheffield S10 2RX

R D Start

A Dube

$S$ S Cross

J C E Underwood

Correspondence to:

Dr R D Start.

Accepted for publication

21 November 1995

Keywords: funeral director, mortuary, necropsy, bereavement.

Clinical necropsy rates in many countries have declined despite widespread acceptance of the potential benefits of necropsies. Most assessments of the factors contributing to this decline have concentrated on the attitudes of pathologists, clinicians and the relatives of deceased patients. ${ }^{1-4}$ It has been suggested that funeral directors may contribute to low necropsy rates by actively discouraging relatives from giving permission for clinical necropsies, but there is little evidence to confirm or refute such practice. In this first study of its type, we have investigated the attitudes and counselling practices of the UK funeral profession regarding necropsies. In addition, the technical and administrative problems experienced by funeral directors in their relations with mortuaries and pathology departments were assessed in detail.

\section{Methods}

The National Association of Funeral Directors (NAFD) is the largest single professional organisation for funeral directors, with a membership of 1631 , representing about $60 \%$ of the UK funeral profession. Members of the NAFD were surveyed by postal questionnaire about a comprehensive range of issues related to necropsy practice including: their beliefs about the purposes of clinical necropsies; the technical and administrative problems experienced in the preparation of necropsied and non-necropsied cases; the questions asked by relatives in relation to necropsies; and the opinions of funeral directors regarding their relations with mortuaries and pathology departments. The questionnaire was designed by a panel of histopathologists and funeral directors. In most sections responses were measured using five point Likert scales (tables 1-5). Other sections recorded general and quantitative information relating to geographical area, workload, proportion of cases subject to necropsy, and types of mortuary served by each funeral director. Space was left for additional comments in all sections. The questionnaires and pre-paid reply envelopes were distributed as inserts within one edition of the monthly magazine of the NAFD, which also contained an editorial highlighting the aims and objectives of the survey. The two subsequent editions of the magazine contained reminder articles.
Results

RESPONSE RATE AND ANALYSIS

In total, 123 questionnaires were returned completed ( $8 \%$ response rate). Response representativeness was assessed by comparisons of the geographical distribution and workloads of respondents with those of the NAFD mem- 
Table 1 Ranked responses to items relating to the question "how important are non-medicolegal (consent) necropsies to the following?"

\begin{tabular}{|c|c|c|c|c|c|c|c|c|}
\hline \multirow[b]{2}{*}{ Ranking } & \multirow[b]{2}{*}{ Item } & \multicolumn{7}{|c|}{ Response values* } \\
\hline & & 1 & 2 & 3 & 4 & 5 & $\begin{array}{l}\text { No } \\
\text { answer }\end{array}$ & $\begin{array}{l}\text { Mean } \\
\text { score }\end{array}$ \\
\hline 1 & Assessment of treatment outcome & 7 & 13 & 26 & 42 & 27 & 8 & $3 \cdot 6$ \\
\hline 2 & Identification of inherited conditions/diseases & 7 & 15 & 31 & 30 & 32 & 8 & 3.6 \\
\hline 3 & Junior pathologist training & 9 & 15 & 22 & 38 & 31 & 8 & 3.6 \\
\hline 4 & Medical research & 13 & 15 & 24 & 31 & 32 & 8 & 3.5 \\
\hline 5 & Information for family & 13 & 29 & 26 & 16 & 33 & 6 & $3 \cdot 2$ \\
\hline 6 & Medical student education & 10 & 22 & 36 & 30 & 19 & 6 & $3 \cdot 2$ \\
\hline 7 & Postgraduate medical education & 11 & 20 & 36 & 28 & 21 & 7 & $3 \cdot 2$ \\
\hline 8 & Confirmation of the cause of death & 26 & 23 & 28 & 13 & 31 & 2 & 3.0 \\
\hline 9 & Death certification accuracy & 48 & 15 & 19 & 15 & 20 & 6 & $2 \cdot 5$ \\
\hline 10 & Medical audit & 40 & 30 & 25 & 11 & 3 & 14 & $2 \cdot 1$ \\
\hline
\end{tabular}

* $1=$ Never; 3 =occasionally; $5=$ always.

bership. No significant differences in geographical distribution were identified between respondents and the NAFD membership $\left(\chi^{2}=\right.$ $2 \cdot 6, p>0 \cdot 05)$ but the proportion of respondents from firms with workloads in excess of 100 funerals per year was significantly larger than the proportion of respondents with workloads below this figure $\left(\chi^{2}=40 \cdot 2, p<0 \cdot 001\right)$. The mean annual workload of respondents was $400 \mathrm{fu}$ nerals (range 35-3050) and the total annual workload was 46163 funerals, which represents about $6 \%$ of all registered deaths in the UK. The mean proportion of cases subjected to necropsies of all types was $30 \%$ (range 5-60).

The majority $(58 \%)$ of respondents represented mixed urban and rural practices, while $33 \%$ were predominantly urban and $9 \%$ were predominantly rural. All types of mortuary were attended by the respondents: $15 \%$ attended public mortuaries outside of hospitals; $56 \%$ attended public mortuaries within hospitals; $30 \%$ attended hospital mortuaries with no public mortuary function, and $25 \%$ attended teaching hospital mortuaries. Seventy seven per cent of respondents had attended two or more necropsies and only $13 \%$ had never attended a necropsy.

The influences of workload, the proportion of cases subjected to necropsy and the types of mortuary served by funeral directors on the responses to all questions were analysed using general linear modelling and none of these parameters was found to have any significant effect on the responses to individual questions.

QUESTIONNAIRE RESPONSES

Attitudes towards clinical necropsies

Clinical necropsies were considered to be important for the assessment of treatment outcome, for the identification of inherited conditions, for medical research, and for junior pathologist training (table 1: items 1-4) but of little importance to medical audit or the accuracy of death certification (items 9 and 10). Other responses were largely neutral, but there was a strong desire among the funeral directors for additional education from pathology departments about the nature and purposes of necropsies (mean score 4.0: $1=$ not desirable at all; $5=$ highly desirable). Several respondents suggested that regular contributions from each profession would benefit the training programme of the other.
Technical and administrative problems associated with necropsied and non-necropsied cases

The commonest technical problems experienced in relation to necropsies were difficulties in embalming, leakage of body fluids and scalpel penetration in visible areas (table 2: items 1-3). Poor reconstruction was an occasional problem (item 4) and some respondents complained about the disposal of materials, such as aprons and gloves, inside necropsied cadavers (item 9). Problems related to specialised necropsy techniques were rare with the exceptions of the non-use of the standard $\mathrm{Y}$ neck incision and paediatric necropsies (table 3: items 1 and 2). Many respondents indicated that they rarely encountered these and other techniques in practice. Occasional problems were also reported in non-necropsied cases and the commonest of these were leakage of body fluids (mean score 3.1: $1=$ never; $5=$ always) and failure to remove cardiac pacemakers and other medical equipment (both mean scores 3.0). Several respondents reported that mortuary technicians made a charge for the removal of cardiac pacemakers and,-although the type of mortuary was found not to influence the overall responses, several funeral directors commented that the larger mortuaries, irrespective of site or type, often provided a lower quality service in comparison with smaller mortuaries.

Forty nine per cent of respondents reported that they are required to pay for body measurements on at least some occasions (mean score 2.5: $1=$ never; $5=$ always). Most funeral directors disagreed with such payments (mean score $1 \cdot 7: 1=$ strongly disagree; $5=$ strongly agree) and agreed with the suggestion that these measurements should be provided free as part of mortuary services (mean score $4 \cdot 5$ ). There was a similar level of disagreement with occasional requests for the payment of cremation form fees in cash (mean score 1.9). These requests were made more frequently by administrative and mortuary staff (both mean scores $2 \cdot 8$ : $1=$ never; $5=$ always) than by hospital doctors (mean score $2 \cdot 5$ ). Requests from pathologists were rare (mean score $1 \cdot 8$ ). Several respondents drew attention to the unhelpful lack of consistency between mortuaries, while others indicated that they preferred to make cash payments in order to avoid bank and postal charges. Occasional problems arose because of these cash payments and two funeral directors 
Table 2 Ranked responses to items relating to the question "how often do you experience the following technical problems in relation to necropsies?"

\begin{tabular}{|c|c|c|c|c|c|c|c|c|}
\hline \multirow[b]{2}{*}{ Ranking } & \multirow[b]{2}{*}{ Technical problem } & \multicolumn{7}{|c|}{ Response values* } \\
\hline & & 1 & 2 & 3 & 4 & 5 & $\begin{array}{l}\text { No } \\
\text { answer }\end{array}$ & $\begin{array}{l}\text { Mean } \\
\text { score }\end{array}$ \\
\hline 1 & Difficulties in embalming bodies & 9 & 14 & 27 & 32 & 35 & 6 & 3.6 \\
\hline 2 & Leakage of fluid/blood & 1 & 14 & 40 & 47 & 20 & 1 & 3.6 \\
\hline 3 & Scalpel penetration in visible areas & 6 & 21 & 52 & 31 & 12 & 1 & $3 \cdot 2$ \\
\hline 4 & Poor reconstruction & 7 & 32 & 38 & 34 & 9 & 3 & $3 \cdot 1$ \\
\hline 5 & Body in an unclean state & 12 & 31 & 40 & 23 & 15 & 2 & $3 \cdot 0$ \\
\hline 6 & Excessive disfigurement & 20 & 43 & 43 & 10 & 4 & 3 & $2 \cdot 6$ \\
\hline 7 & Medical equipment left attached to outside of body & 39 & 19 & 29 & 28 & 6 & 2 & $2 \cdot 5$ \\
\hline 8 & Inadequate refrigeration with early decomposition & 34 & 54 & 21 & 8 & 1 & 5 & $2 \cdot 1$ \\
\hline 9 & Non-medical equipment left inside body & 44 & 33 & 26 & 13 & 5 & 2 & $2 \cdot 1$ \\
\hline 10 & External damage due to transportation & 47 & 49 & 14 & 7 & 0 & 6 & $1 \cdot 8$ \\
\hline 11 & Failure to enclose infective cases in body bags & 59 & 33 & 18 & 8 & 1 & 4 & 1.8 \\
\hline 12 & Cardiac pacemaker left in body & 63 & 27 & 14 & 8 & 5 & 6 & $1 \cdot 8$ \\
\hline
\end{tabular}

* $1=$ Never; 3 = occasionally; 5 = always.

Table 3 Ranked responses to items relating to the question "how often do you experience techncial problems in relation to the following special necropsy techniques?"

\begin{tabular}{|c|c|c|c|c|c|c|c|c|}
\hline \multirow[b]{2}{*}{ Ranking } & \multirow[b]{2}{*}{ Special necropsy technique } & \multicolumn{7}{|c|}{ Response values* } \\
\hline & & 1 & 2 & 3 & 4 & 5 & $\begin{array}{l}\text { No } \\
\text { answer }\end{array}$ & $\begin{array}{l}\text { Mean } \\
\text { score }\end{array}$ \\
\hline 1 & Non-use of standard $\mathrm{Y}$ neck incision & 30 & 23 & 30 & 15 & 16 & 9 & $2 \cdot 7$ \\
\hline 2 & Perinatal/infant necropsy & 36 & 32 & 23 & 9 & 14 & 9 & $2 \cdot 4$ \\
\hline 3 & Removal of eye & 56 & 30 & 26 & 3 & 0 & 8 & $1 \cdot 8$ \\
\hline 4 & Limited necropsy & 63 & 31 & 15 & 3 & 1 & 10 & 1.7 \\
\hline 5 & Removal of spinal cord & 65 & 28 & 13 & 5 & 2 & 10 & 1.7 \\
\hline 6 & Removal of femur & 67 & 32 & 14 & 1 & 0 & 9 & 1.6 \\
\hline 7 & Needle core biopsy necropsy & 78 & 22 & 9 & 1 & 1 & 12 & $1 \cdot 4$ \\
\hline 8 & Removal of finger & 94 & 12 & 5 & 3 & 0 & 9 & $1 \cdot 3$ \\
\hline
\end{tabular}

* $1=$ Never; 3 = occasionally; 5 = always.

Table 4 Ranked responses to items relating to the question "how often do you experience the following administrative problems?"

\begin{tabular}{|c|c|c|c|c|c|c|c|c|}
\hline \multirow[b]{2}{*}{ Ranking } & \multirow[b]{2}{*}{ Administrative problem } & \multicolumn{7}{|c|}{ Response values* } \\
\hline & & 1 & 2 & 3 & 4 & 5 & $\begin{array}{l}\text { No } \\
\text { answer }\end{array}$ & $\begin{array}{l}\text { Mean } \\
\text { score }\end{array}$ \\
\hline 1 & Inflexible times for the removal of bodies & 17 & 23 & 28 & 34 & 19 & 2 & $3 \cdot 1$ \\
\hline 2 & Delays in release of bodies after consent necropsies & 24 & 32 & 32 & 28 & 5 & 2 & $2 \cdot 7$ \\
\hline 3 & $\begin{array}{l}\text { No clearly identifiable person responsible for mortuary } \\
\text { services (excluding mortuary technicians) }\end{array}$ & 35 & 35 & 17 & 15 & 19 & 2 & $2 \cdot 6$ \\
\hline 4 & Incorrectly completed cremation form & 12 & 48 & 40 & 20 & 0 & 3 & $2 \cdot 6$ \\
\hline 5 & Uncertainty about removal of cardiac pacemaker & 30 & 41 & 28 & 14 & 6 & 4 & $2 \cdot 4$ \\
\hline 6 & $\begin{array}{l}\text { Delays in release of bodies after non-forensic } \\
\text { medicolegal necropsies }\end{array}$ & 24 & 43 & 31 & 20 & 2 & 3 & $2 \cdot 4$ \\
\hline 7 & Delay of funerals because of consent necropsies & 37 & 38 & 26 & 18 & 3 & 1 & $2 \cdot 3$ \\
\hline 8 & Failure to identify potentially infective cases & 35 & 34 & 32 & 13 & 3 & 6 & $2 \cdot 3$ \\
\hline 9 & Delay of funerals because of medicolegal necropsies & 28 & 45 & 29 & 16 & 2 & 3 & $2 \cdot 3$ \\
\hline 10 & Incorrectly completed death certificate & 32 & 48 & 34 & 7 & 0 & 2 & $2 \cdot 1$ \\
\hline 11 & Failure to appreciate specific religious requirements & 61 & 35 & 13 & 7 & 2 & 5 & 1.8 \\
\hline 12 & Lack of identification & 75 & 29 & 17 & 1 & 0 & 1 & 1.5 \\
\hline
\end{tabular}

$* 1=$ Never; $3=$ occasionally; $5=$ always

reported that local mortuaries operated policies of requiring cremation form fees in cash before allowing the removal of bodies. Other administrative problems were relatively uncommon except for inflexibility in times for the removal of cadavers which represented the commonest administrative complaint of respondents (table 4: item 1).

\section{Relationships between relatives and funeral directors}

Funeral directors reported that relatives do occasionally seek their advice about necropsies. There were no differences in the frequency of advice sought in relation to clinical or medicolegal necropsies (both mean scores 3.0: $1=$ never; $5=$ always). The commonest areas of necropsy practice discussed with relatives were concerns about funeral delay and dis- figurement, requests for more information about the purpose of necropsies and concern about the involvement of the coroner or equivalent authority (table 5: items 1-4). Concerns about religious matters were rare (item 8 ). Sixty six per cent of funeral directors indicated that they have occasionally counselled relatives against giving permission for necropsies (mean score 2.6: $1=$ never; $5=$ always), most commonly because of family concerns about funeral delay. Some respondents cited the failure to inform relatives of clinical necropsy findings as a reason for counselling against providing necropsy consent. Fifty five per cent of funeral directors reported that they had counselled relatives to give necropsy consent on occasions (mean score $2 \cdot 0$ ) and the commonest reason was to provide more information for the family. Funeral directors reported that relatives only occasionally take their advice regarding nec- 
Table 5 Ranked responses to items relating to the question "which of the following areas of necropsy practice do relatives seek to discuss with you?"

\begin{tabular}{|c|c|c|c|c|c|c|c|c|}
\hline \multirow[b]{2}{*}{ Ranking } & \multirow[b]{2}{*}{ Area of practice } & \multicolumn{7}{|c|}{ Response values* } \\
\hline & & 1 & 2 & 3 & 4 & 5 & $\begin{array}{l}\text { No } \\
\text { answer }\end{array}$ & $\begin{array}{l}\text { Mean } \\
\text { score }\end{array}$ \\
\hline 1 & Concern about delay of funeral & 1 & 15 & 35 & 52 & 19 & 1 & $3 \cdot 6$ \\
\hline 2 & $\begin{array}{l}\text { Concern about involvement of the coroner or } \\
\text { equivalent authority }\end{array}$ & 2 & 16 & 51 & 38 & 15 & 1 & $3 \cdot 4$ \\
\hline 3 & Information about purpose of necropsy & 5 & 23 & 42 & 39 & 11 & 3 & $3 \cdot 2$ \\
\hline 4 & Concern about disfigurement & 11 & 23 & 42 & 33 & 13 & 1 & $3 \cdot 1$ \\
\hline 5 & $\begin{array}{l}\text { Advice regarding giving permission for a consent } \\
\text { necropsy }\end{array}$ & 12 & 38 & 39 & 28 & 5 & 1 & $2 \cdot 8$ \\
\hline 6 & Concern about confidentiality & 25 & 41 & 29 & 21 & 5 & 2 & $2 \cdot 5$ \\
\hline 7 & $\begin{array}{l}\text { Details about the technical procedures involved in } \\
\text { necropsies }\end{array}$ & 22 & 47 & 43 & 6 & 2 & 3 & $2 \cdot 3$ \\
\hline 8 & Concern about religious matters & 49 & 45 & 16 & 8 & 2 & 3 & 1.9 \\
\hline
\end{tabular}

$* 1=$ Never; 3 = occasionally; 5 = always.

ropsy consent (mean score $3 \cdot 2$ ). Several respondents indicated that the decision to give permission for clinical necropsies has usually been made prior to any contact with a funeral director. In general, the negative attitudes of hospital medical and administrative staff were thought to have more influence on the decision of the relatives than the opinions of funeral directors.

\section{Relations among funeral directors, mortuaries and pathology departments}

Funeral directors appeared to be quite satisfied both with their relations with local pathology departments (mean score 3.5: $1=$ not satisfied at all; $5=$ highly satisfied) and with current arrangements for dealing with problems arising from mortuary practices (mean score $3 \cdot 1$ ). There was strong support for the suggestion of a code of practice to cover relations between mortuaries and the funeral profession (mean score 4.4: $1=$ not support at all; $5=$ strongly support). Many respondents also indicated that they would support the creation of local working groups to monitor relations between funeral directors and other relevant groups.

\section{Discussion}

This survey of the attitudes and beliefs of funeral directors regarding necropsies and mortuary practices is the most comprehensive study of its type ever attempted in the UK. Despite the low response rate, our observations are based on a large sample of funeral directors comprising $5 \%$ of all funeral directors in the UK. The reasons for the poor response rate are probably multi-factorial and include the length of the questionnaire, the method of distribution and a lack of interest amongst some funeral directors. Although the large sample of funeral directors was found to be representative of the NAFD membership in terms of geographical distribution, the low response rate necessitates cautious interpretation of our findings because of possible bias among the respondents who tended to represent funeral directors with annual workloads in excess of 100 funerals. We cannot exclude the possibility that non-respondents differed from respondents in their attitudes and experiences. However, it is probable that non-respondents experienced at least some of the problems in practice and that our findings are therefore likely to be conservative. The NAFD is the largest single professional organisation for funeral directors and, although our results should be generalised to non-NAFD members with care, we believe that the attitudes and experiences of this large sample of funeral directors are representative of the whole funeral profession in the UK

Funeral directors believed that necropsies were important for the assessment of treatment outcome, the identification of inherited conditions and junior pathologist training, but necropsies were considered to be of little importance to medical audit which may reflect a lack of awareness of this developing clinical activity. Although $77 \%$ of funeral directors had attended two or more necropsies, most respondents felt that they were not provided with enough information about the nature and purpose of necropsies during their training. Further education was considered to be desirable by funeral directors, particularly if this were to be provided in conjunction with local pathology departments. Many respondents indicated that they would support any initiatives to improve their relationships with the medical profession, including pathologists, and hoped that these would provide opportunities to discuss those aspects of hospital and mortuary practices that directly affect the work of funeral directors.

The commonest technical problems associated with necropsied cases were difficulties in embalming cadavers caused by damage to peripheral arteries. Embalming is performed in a variably high proportion of cases $(30-70 \%)$ in the UK because of the relatively long time between death and disposal. ${ }^{5}$ The embalming of cadavers reduces post mortem staining and retards decomposition until the completion of the final rites. Some pathologists and mortuary technicians may be unaware both of the frequency with which embalming is performed and the techniques which are involved in the procedure. Necropsies will always complicate embalming but problems could be minimised with appropriate education and training. Leakage of body fluids from cadavers was equally common in necropsied and non-necropsied cases. This may reflect the inadequacy of the last offices, which include the packing of body orifices, that are performed by nursing and mortuary staff. Some hospitals no longer per- 
form the last offices and funeral directors have reported the reception of increasing numbers of unprepared bodies. ${ }^{6}$

Although previous studies have found the failure to identify potentially infective cadavers to be a significant problem, ${ }^{6}$ our observations indicate that this may be an uncommon occurrence. Concerns regarding patient confidentiality can mean that funeral directors are often not made aware of the presence of potential infective hazards until after the receipt of documentation for cremation, if at all. There can also be confusion regarding which notifiable diseases actually represent an infective risk to the funeral profession. ${ }^{56}$ Funeral directors often receive conflicting advice from hospitals regarding such cases and deaths involving septicaemia can cause considerable anxiety if discovered after completion of the embalming process. Body bags are now commonly used as a precaution for cases considered to represent an infective risk and to transport leaking or offensive bodies. The use of body bags is increasing with some hospitals adopting universal precautions, including body bags, for all cadavers. Such practice has serious repercussions for funeral directors who must be able to distinguish clearly the few high risk cases which may not be suitable for viewing or further handling. The denial of viewing by relatives or washing by religious leaders in some ethnic groups can be deeply distressing and may be unnecessary in some cases. Body bags can also facilitate decomposition by slowing cooling and some cannot be cremated because of dioxin emission regulations. ${ }^{6}$ Clear guidelines exist for prevention of infection in mortuaries but these do not currently apply to funeral directors' premises. $^{78}$ Better communication between all personnel involved in the disposal of the dead is required if cadavers are to be handled efficiently and in the safest possible manner.

Occasional administrative problems were reported by funeral directors and the commonest of these was inflexibility over times for the removal of bodies. Particular family circumstances and some religions may require adherence to specific timing restrictions which can be honoured by expediting necropsies whenever possible. ${ }^{9}$ Problems arising from the failure to appreciate specific religious requirements regarding the preparation and disposal of the dead were rare in this study and many respondents reported the operation of mortuary policies designed to accommodate the requirements of most religions. Possible delay of funeral arrangements caused by necropsy represented the commonest concern of relatives reported to funeral directors. However, funeral directors indicated that necropsy related delays in release of bodies after necropsies and subsequent funeral arrangements were rare, with no differences between medicolegal and clinical necropsies. Studies from other countries have reported significant delays in obtaining necropsied cases from hospital and the different experience in this country may be due to the relatively long period between death and disposal which reduces the influence of necropsy related delays. ${ }^{1011} \mathrm{~A}$ recent audit of our own clinical necropsy service found that necropsy related interference with funeral arrangements was rare. ${ }^{12}$

Funeral directors reported that relatives do occasionally seek their advice or additional information regarding all types of necropsy. The commonest areas of necropsy practice for discussion include the purpose of the necropsy examination and concerns about funeral delay, disfigurement and the involvement of the coroner or equivalent authority. The public has considerable understanding of the procedures involved in necropsy and to some extent the role of necropsies, ${ }^{13}$ but it is of some concern that relatives have to seek additional information from the funeral profession rather than from the doctors responsible for requesting necropsies or referring deaths to coroners. In many hospitals administrative staff provide a valuable and often unofficial information service which reduces the distress caused to relatives. All those who come into contact with bereaved relatives, including funeral directors, should have an accurate appreciation of modern necropsy practice. The possible benefits of necropsy to the family and society should be understood and explained without expressions of personal indifference or aversion. Those who cannot support a role for necropsies may still have to inform relatives of the requirement for a medicolegal necropsy and it is important that common misconceptions about the procedure are recognised and corrected in such instances. Many funeral directors commented that reasons for the involvement of coroners are often not explained to next of kin. Some relatives will incorrectly assume that there must be suspicious circumstances surrounding the death while others believe that they themselves must be under investigation. All doctors should be able to recognise and explain those circumstances which require deaths to be reported to coroners. ${ }^{1415}$

In this study, funeral directors admitted that on occasions they have counselled relatives about their decision to give permission for clinical necropsies, but there was little difference in the frequency with which they counselled relatives for and against giving consent. The commonest reported reasons given for this counselling were a family's wish for further information and a family's concerns about disfigurement, respectively. The frequency with which funeral directors counsel relatives against a clinical necropsy is low in comparison with that reported in the only other similar study. ${ }^{10}$ Although our findings may represent an underestimate of actual practice, we would accept the view of some respondents that some decisions concerning necropsy consent are taken before any direct contact with a funeral director and are therefore made without reference to the opinions of funeral directors. The public believes that necropsies are important, ${ }^{13}$ and many funeral directors felt that the negative attitudes of hospital staff, medical or otherwise, towards necropsies were far more influential to the decision of relatives than the opinions of the funeral profession. The influence such negative 
attitudes can have on the public should not be underestimated; it is unacceptable that members of the medical community, including allied professions such as nursing, are not only unaware of the importance of necropsies but can also influence relatives through personal misconceptions of necropsy practice. The present study indicates that whilst funeral directors may have contributed to the decline in clinical necropsy rates, they represent a relatively minor factor in what is clearly a complex problem. Nevertheless, a positive image of necropsy should be introduced into funeral director training programmes in conjunction with local pathology departments.

Despite the low response rate, our observations are the largest survey of the UK funeral profession's beliefs and experiences regarding modern necropsy and mortuary practices. Funeral directors provide an important service to bereaved relatives and are committed to the highest possible standards of practice. We firmly believe that a similarly high level of service should be provided by mortuaries and departments of pathology. This study has usefully identified several areas in which the relations among funeral directors, mortuaries and pathology departments could be improved and we hope that our findings might generate further discussions of these important issues, including the possible introduction of a national code of practice.
We thank the National Association of Funeral Directors for their assistance and the funeral directors who participated in the study.

1 Stubbs F, Start RD, Hector-Taylor MJ, Cotton DWK. The attitudes of junior pathologists towards the autopsy. $f$ Pathol 1992;166:413-15.

2 Start RD, McCulloch TA, Silcocks PB, Cotton DWK. Attitudes of senior pathologists towards the autopsy. $\mathcal{f}$ Pathol 1994;172:81-4.

3 Start RD, Hector-Taylor MJ, Cotton DWK, Startup M, Parsons MA, Kennedy A. Factors which influence autopsy requests: a psychological approach. 7 Clin Pathol 1992; 45:254-7.

4 McPhee SJ, Bottles K, Lo B, Saika G, Crommie D. To redeem them from death. Reactions of family members redeem them from death. Reactions of

5 Healing TD, Hoffman PN, Young SEJ. The infection hazards of human cadavers. Communicable Disease Report 1995;5:R61-8

6 Young SEJ, Healing TD. Infection in the deceased: a survey of management. Communicable Disease Report 1995;5:R6973.

7 Health Services Advisory Committee. Safety in health service laboratories: safe working and the prevention of infection in the mortuary and the post-mortem room. London: HMSO, 1991.

8 Department of Health. Mortuary and post-mortem room (Health Building Note 20). London: HMSO, 1990.

9 Green J, Green M. Dealing with death. Practices and procedures. London: Chapman and Hall, 1992.

10 Heckerling PS, Williams MJ. Attitudes of funeral directors and embalmers toward autopsy. Arch Pathol Lab Med 1992;116:1147-51.

11 Rispler-Chaim V. The ethics of post-mortem examinations in contemporary Islam. $\mathcal{F}$ Med Ethics 1993;19:164-8.

12 Start RD, Sherwood SJ, Angel CA, Kent G. An audit of next of kin satisfaction with a clinical autopsy service. $\mathcal{f}$ Pathol (in press)

13 Start RD, Saul CA, Cotton DWK, Mathers NJ, Underwood JCE. Public perceptions of necropsy. $\mathfrak{f}$ Clin Pathol 1995; 48E. Public

14 Start RD, Delargy-Aziz Y, Dorries CP, Silcocks PB, Cotton DWK. Clinicians and the coronial system: ability of clinicians to recognise reportable deaths. BMF 1993;306:103841.

15 Start RD, Usherwood TP, Carter N, Dorries CP, Cotton DWK. General practitioners' knowledge of when to refer deaths to a coroner. $B r \mathcal{F}$ Gen Pract 1995;45:191-3. 